\title{
6 年制薬学部卒業時に必要とされる資質の具体例とその評価方法
}

\author{
高 橋＼cjkstart寛, ${ }^{a}$ 小佐野博史 ${ }^{*, b}$
}

\section{Introduction of Outcome-based Education in Pharmaceutical Education in Japan}

\author{
Hiroshi Takahashi ${ }^{a}$ and Hiroshi Kosano ${ }^{*, b}$ \\ ${ }^{a}$ Miyoshi Pharmacy; 6-20 Omagari Fukuzumi-cho, Daisen, Akita 014-0014, Japan: and \\ ${ }^{b}$ Teikyo University; 2-11-1 Kaga, Itabashi-ku, Tokyo 173-8605, Japan.
}

(Received July 30, 2014)

\begin{abstract}
Although Japanese medical and pharmaceutical educators have been interested in outcome-based education (OBE) in recent years, there are still many difficulties and problematic concepts involved in curriculum building, especially in determining objectives and assessment methods. From 2015, OBE will be incorporated in a model core curriculum of pharmaceutical education in Japan. In this paper, we will introduce the outline of an operative sample of OBE derived from the National Competency Standards Framework for Pharmacists in Australia. The products shown in this paper are examples of standards, elements, and some rubric scales and descriptors in the domain of "Practical ability in pharmaceutical therapy", as presented by the Ministry of Education, Culture, Sports, Science and Technology of Japan, and as proposed by many participants attending The Pharmaceutical Society of Japan's 3rd advanced workshop for pharmaceutical educators in 2013. We expect a helpful outline will enable each educational institution to design an appropriate OBE curriculum.
\end{abstract}

Key words_ outcome-based education; pharmaceutical education; model core curriculum; rubric

\section{1. はじめに}

平成 25 年度に改訂された薬学教育モデル・コア カリキュラムは, 従来の日本薬学会の薬学教育モデ ル・コアカリキュラムと, 文部科学省の実務実習モ デル・コアカリキュラムが一体化するとともに, 学 習成果基盤型教育 (outcome-based education; OBE) の考え方が取り入れられた. Harden らが 1999 年 に報告1)した OBE は，今までの一般目標（general instructional objective; GIO）と到達目標（specific behavioral objective; SBO）をコアとしたプロセス 基盤型教育と異なり，学習成果（アウトカム）を重 視する教育である。薬学教育モデル・コアカリキュ ラム平成 25 年度改訂版においては, 6 年制薬学教 育課程の修了時に薬剤師として求められる 10 の基 本的な資質を示した. ${ }^{2)}$ 各大学はこの 10 の基本的な

\footnotetext{
a夕よし薬局大曲厚生医療センター前（†014-0014 秋 田県大仙市大曲福住町 6-20), $b$ 帝京大学薬学部薬物治 療学研究室 (T173-8605 東京都板橋区加賀 2-11-1)

*e-mail: h-kosano@pharm.teikyo-u.ac.jp

本総説は, 日本薬学会第 134 年会シンポジウムS33 で 発表した内容を中心に記述したものである。
}

資質を身につけるための具体的で実践的なカリキュ ラムを構築し, 卒業時に学生がこれらの資質を身に つけているか評価する必要がある.

OBE に基づいたカリキュラム構築プロセスで は，まず学習成果（アウトカム）として資質を特定 するが，それぞれについて修得度を評価できるよ う, 資質は実践的な能力として具体化する必要があ る。“薬学教育モデル・コアカリキュラム 平成 25 年度改訂版” で提示された 10 の資質は，オースト ラリアのコンピテンシープログラム3)のドメイン (Domain) に相当する.オーストラリアのコンピ テンシープログラムは, ドメインの下位にスタン ダード（Standard），その下位にエレメント（Element）という概念を階層的に構築している. 第 3 回薬学教育者のためのアドバンストワークショップ （WS）においては，10の資質から「薬剤師として の心構え」,「薬物療法における実践的能力」,「研究 能力」の 3 つを選んでスタンダードとエレメントを 作成し，その評価方法について検討した。 そこで本 稿ではテーマの 1 つである「薬物療法における実践 的能力」について, スタンダードとエレメントに相 


\section{オーストラリアの例}

\section{Domain 6}

Deliver primary and preventive health care(資質)

6.1 Assess primary health care needs

6.2 Deliver primary health care

6.3 Contribute to public and preventive health(スタンダード)

1. Understand public health issues

2. Promote the health of consumers

3. Support consumer health literacy and selfmanagement

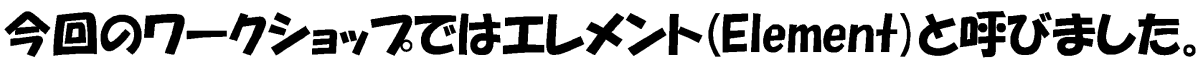

Fig. 1. National Competency Standards Framework for Pharmacists in Australia (2010)

当する概念はどのようなものか，そしてどのような 評価が可能なのか，具体的な例を挙げて紹介する.

2. オーストラリアの例

オーストラリアでは, 薬学教育モデル・コアカリ キュラムに相当する National Competency Standards Framework for Pharmacists in Australia ${ }^{3)}$ とい うものがある，その中では，基本的な資質に相当す る概念が，ドメインとして 8 項目定義されている. そして各ドメインの下位により具体的な項目がスタ ンダードとして複数定義され，さらに各スタンダー ドの下位に具体的な項目がエレメントとして複数記 載されている。そこで，今回のWSでもこれらを スタンダードとエレメントと呼ぶことにした（Fig. 1).

3. アウトカムでは何を評価するかーパフォーマ ンスの評価一

卒業時のアウトカムを評価するということは，決 して 1000 項目以上ある SBOs をすべて卒業時に評 価するわけではない。つまり，プロセス基盤型教育 との大きな相違点は，OBEではタキソノミー（知 識，技能，態度）にとらわれない総合的な能力 (OBE ではパフォーマンス評価と位置付けている) を卒業時に評価する必要がある。この際, 学生は初 年次から卒業時のアウトカムを知っており, 常に ゴールを見据えて学び続けることが大切である。こ のため, 学びの可視化, すなわち評価の観点を可視 化することにより, 教員と学生が目標を共有し, そ
の成長段階を具体的に認識することが必要となる.

4. パフォーマンス評価の定義と特徵

パフォーマンス評価とは，「ある特定の文脈のも とで，様々な知識，技能などを持ちながら行われる 学習者自身の作品や実演（パフォーマンス）を直接 評価する方法」であり, Hart によると「学生のパ フォーマンスやその事例を, 設定されたパフォーマ ンスの基準に基づいて体系的に直接観察し評価す る」と定義されている. ${ }^{4)}$ 薬学教育に置き換えれば, 教員や医療現場の指導薬剂師が学生の能力を評価す る上で，学生に期待する姿を具体的に記述したもの と言うこともできる，実際には，学生にある具体的 な場面を，実地，模擬など，その時点で可能な状況 で設定し，薬物治療モニタリングや服薬指導，情報 提供などのパフォーマンスを行わせてみて，それを 学生に期待する姿と照らし合わせて直接評価するこ とを意味している. 現在の薬学共用試験の客観的臨 床能力試験 (objective structured clinical examination；OSCE）と異なる点は，評価の場面や領域を 細かく設定せず，また技能・態度のみを評価するの ではないことで, 全体の流れの中で知識も含めた総 合的な能力を評価するところが, 文脈性あるいは複 合性という言葉で説明されている。このため，パ フォーマンスの背後に隠れている専門性と繰り返し による振り返りが, 学生の目標達成度の上昇につな がるため, 評価基準の作成と専門家としてのプロ フェッショナリズムが必要となる. 


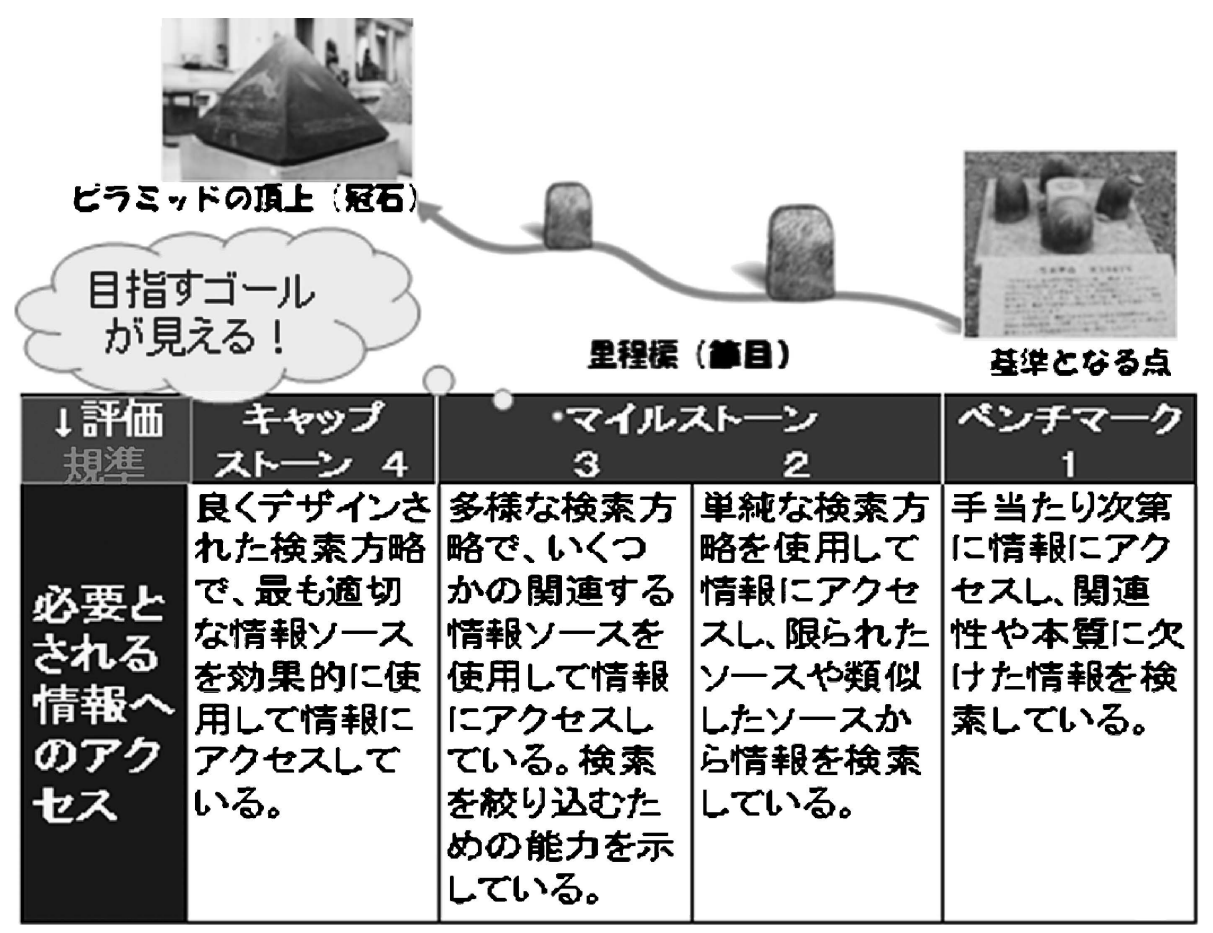

Fig. 2. Imaging of Rubric Scale and Issue

\section{5. ルーブリック評価の実例}

ルーブリック評価の具体例を Fig. 2 に示した. 左欄の「必要とされる情報へのアクセス」は，アウ トカムの 1 つであるスタンダードの 1 例で，学生が 何を修得するのかを示す規準（規範となる標準）で ある。一方，横に記載されたキャップストーン からベンチマーク（1）は，学生が到達しているパ フォーマンスのレベル, 特徵の基準（比較判断の標 準) を文章で記述してある。記述した文章には，評 価の視点，あるいは観点が含まれる，学生はキャッ プストーンを目標とし, その基準に到達すべくベン チマークから学習してゆく.

\section{6. 作業方法}

本 WS では，資質の 1 つである「薬物療法にお ける実践的能力：薬物療法を主体的に計画, 実施, 評価し, 安全で有効な医薬品の使用を推進するため に，医薬品を供給し，調剤，服薬指導，処方設計の 提案等の薬学的管理を実践する能力を有する」につ いて，まずスタンダードとエレメントに相当する内 容を小グループ討議にて検討し，次にその達成度を 評価するために，学習成果の適切な評価方法の 1 つ であるルーブリック評価法を作成した。

6-1. スタンダードの作成、「薬物療法におけ る実践的能力」という資質が具体的に「薬剤師とし
てどのようなことを実践する」能力か，基本的な 5 つ前後の内容に集約し，「〜を実践する」というパ フォーマンスを表す表現を用いて作成した。

6-2. エレメントの作成 スタンダードの中か ら代表的なものを選び，内容をより具体化したエレ メントを複数作成した. エレメントもスタンダード と同様に「〜を実践する」などパフォーマンスを表 す動詞を用いた.

6-3. パフォーマンス評価法としてのルーブリッ クの作成パフォーマンス評価方法の 1 つとし て，ルーブリック評価を本 WS ではとり上げた. ${ }^{5)}$ ルーブリック評価とは「目標に準拠した評価」, す なわちアウトカムを評価するための「基準」を用い た評価方法である，技能，態度を評価するにあた り，客観性を高めるために用いた評定尺度の応用版 と考えることができる、マトリクス形式で示す評価 指標で, 縦には評定尺度における項目の代わりに何 を学習するのかを示すアウトカムである評価規準を 示し, 横には数字で 4-6 段階作成していた尺度の代 わりに到達レベルを示す具体的な評価基準を記載す る. 評価基準は, 学習者のパフォーマンスの成功の 度合いを示す尺度と，それぞれの尺度に求めるパ フォーマンスの特徵を説明する記述語から構成され ている．これらは被評価者である学生に分かる形で 


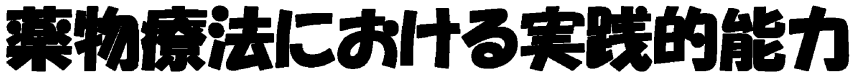

1. 患者の病態を把握する。 スタンダード

1-1. 疾病について理解する。

1－2．身体所見を収集し、患者特性を理解する。

1ー3．フィジカルアセスメントを実践する。

2. 薬物療法について提案する。

2-1. 薬物・薬剤について精通する。

2-2. 全体の治療計画を理解する。

2-3. 処方設計を作成する。

2-4. 医師・看護師などとコミュニケーションをとる。

3. 適切に薬绪を供給する。

3ー1．正しく調剂をする。

3-2. 適切に疑義照会する。

3ー3．適切に服薬指望する。

4. 最新の情報を活用する。

4-1. 副作用情暂志收策する。

4-2. 新しい医薬品や治療法を理解する。

5. 薬効と副作用を統合して薬物㞠法を評価する。

$5-1$. 薬効と副作用をそれぞれ評価する。

5-2. フィジカルアセスメントを適切に利用する。

5ー3．リスク - ベネフィットを理解する。

Fig. 3. Examples of Standards and Elements from the 3rd Advanced Workshop for Pharmaceutical Educators

Table 1. Example of Rubric from the 3rd Advanced Workshop for Pharmaceutical Educators

\begin{tabular}{|c|c|c|c|c|}
\hline \multicolumn{5}{|c|}{ グループ名：II-A 資質：薬物療法における実践的能力 } \\
\hline $\begin{array}{c}\text { スタンダード } \\
\downarrow\end{array}$ & $\begin{array}{c}\text { キャップストーン } \\
4\end{array}$ & \multicolumn{2}{|c|}{ マイルストーン } & $\begin{array}{c}\text { ベンチマーク } \\
1\end{array}$ \\
\hline $\begin{array}{l}\text { 1. 患者の病態を把握 } \\
\text { する. }\end{array}$ & $\begin{array}{l}\text { 身体所見や患者特性を } \\
\text { 基に, 患者の病態を把 } \\
\text { 握できる. } \\
\text { 必要に応じてフィジカ } \\
\text { 勇セスメントを実践 } \\
\text { できる. }\end{array}$ & 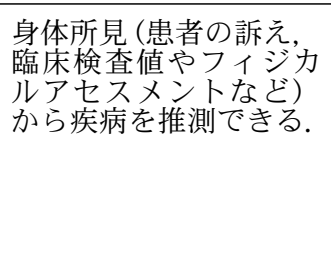 & $\begin{array}{l}\text { 臨床検査值と疾病との } \\
\text { 関係を理解している. } \\
\text { 薬歴・カルテから患者 } \\
\text { 背患者特性を抽出 } \\
\text { できる. }\end{array}$ & $\begin{array}{l}\text { 生体の機能や分子の基 } \\
\text { 礎的知識を持つている. } \\
\text { 疾病や臨床検査に関する } \\
\text { 基礎知識を持つている. } \\
\text { 簡単なバイタルチェッ } \\
\text { ク (血圧・脈拍確認) } \\
\text { ができる. }\end{array}$ \\
\hline $\begin{array}{l}\text { 3. 適切に薬剂を供給 } \\
\text { する. }\end{array}$ & $\begin{array}{l}\text { 処方箋を基に患者に最 } \\
\text { 適な調剤が正しくざき } \\
\text { る.患者にわかり易く } \\
\text { 服薬指導できる.必要 } \\
\text { ならば適切に疑義照会 } \\
\text { できる. }\end{array}$ & $\begin{array}{l}\text { 薬物併用時の問題点を } \\
\text { 理解している. } \\
\text { 薬剤の情報を平易な言 } \\
\text { 葉で表現できる. }\end{array}$ & $\begin{array}{l}\text { 処方箋の不備を発見で } \\
\text { きる. } \\
\text { 薬剂毎に服薬時の注意 } \\
\text { 事項を確認できる. 無 } \\
\text { 菌調剂ができる. }\end{array}$ & $\begin{array}{l}\text { 処方箋の内容を理解し, } \\
\text { 計数・計量調剤を正し } \\
\text { く行うことができる. }\end{array}$ \\
\hline
\end{tabular}

示し, 学生と共有する (Fig. 2).

平成 22 年 8 月に発表された中央教育審議会答 申6)でも, 大学で速やかに取り組むことが求められ る事項として，学修ポートフォリオとともにルーブ リック評価が盛り込まれている。本 WS では，作 成したスタンダードとエレメントを用いてルーブ リック評価表を作成した。

7. プロダクト

グループ討議により作成された「薬物療法におけ る実践的能力」（資質）に関するスタンダード例と エレメント例を Fig. 3 に示した。 スタンダードと
して以下の 5 つが提案された $: 1$. 患者の病態を把 握する，2. 薬物療法について提案する， 3. 適切に 薬剤を供給する，4. 最新の情報を活用する，5. 薬 効と副作用を統合して薬物療法を評価する，スタン ダード「1. 患者の病態を把握する」に関してはさ らに以下の 3 つのエレメントが作成された : 1-1. 疾 病について理解する, 1-2. 身体所見（臨床検査值 バイタルサインなど)，年齢，薬歴から患者特性を 理解する，1-3. フィジカルアセスメントを実践す る. 紹介例では，「薬物療法における実践的能力」 の全体像として 5 つのスタンダード, 15 のエレメ 
ントとなつた (Fig. 3).

ルーブリック評価表については，「薬物療法にお ける実践的能力」について作成したスタンダードの うち「1. 患者の病態を把握する」，「3. 適切に薬剤 を供給する」の 2 つにつて，エレメントの段階的 な達成度を視野に入れて作成した（Table 1)，2つ のスタンダード「患者の病態を把握する」と「適切 に薬剤を供給する」に対して，それぞれキャップス トーンを設定し，ここに到達するまでの段階的な基 準を示したマイルストーンとベンチマークがエレメ ントの内容を取り入れて示されている。これは 1 つ の例示であり，各大学において独自に基準を検討し て設定することを提案する。

\section{8. まとめ}

“薬学教育モデル・コアカリキュラム 平成 25 年 度改訂版”における「薬学生が卒業時までに身につ けておく基本的な 10 の資質」のうち「薬物療法に おける実践的能力」について，オーストラリアのコ ンピテンシープログラムを参考に，スタンダード, エレメントという階層概念を基に構築したプロダク トの 1 例を示した.

また，アウトカムの 1 つの評価方法として，ルー ブリック評価を紹介した。 ルーブリック評価を卒業 時のアウトカム評価に導入するには，「通常の定量 的評価に比べて手間がかかる」，「教科の壁に阻まれ 評価者間の合意が難しい」，「尺度の設定が難しい」 などの問題点が数多く存在することは事実である が，それに勝る数多くの利点が存在する．利点とし て最も強調されるのは，卒業時の評価基準を入学時 などなるべく早い段階から学生に提示できることで ある。これにより入学時から学生は自分の立ち位置 を自覚するようになり，これから昇るらせん型カリ キュラムが見えるようになり，学びの動機と目標が 明確になる。また，学年が進行しても同じ評価表を 用いることにより，教科の異なる教員間で教育目標 が共有され，らせん型カリキュラムの有効性につい ても振り返ることができる，一方，学生は自らの成 長と欠けている点を認識することができ，何が足り ないのか，なぜその評価なのか，どうすれば評価が 上がるかを認識し，より高いところに向かおうと努 力する，この，自分を評価するという姿勢を醸成す
ることにより，自己教育力の育成が達成されると考 えられる，各大学で faculty development 等を通し て有効な利用が行われることが薬学教育の成功の鍵 であると信じている。

平成 25 年 10 月に東京で開催された「薬学教育者 のためのアドバンスト WS」のプロダクト7)を例に,

「薬物治療における実践的能力」という資質に限定 して概説したが，あくまで例示であり，各大学での 評価における参考になれば幸いである.

利益相反＼cjkstart開示すべき利益相反はない.

\section{REFERENCES}

1) Harden R. M., Crosby J. R., Davis M. H., Med. Teach., 21, 7-14 (1999).

2) Ministry of Education, Culture, Sports, Science and Technology. "Model core curriculum for pharmacy education.": 〈http://www. mext.go.jp/b menu/shingi/chousa/koutou/ 47 / siryo / _ icsFiles / afieldfile / 2014 / 01 / 06 / 1342142_05.pdf $\rangle$, cited 30 June, 2014.

3) Pharmaceutical Society of Australia, "National Competency Standards Framework for Pharmacists in Australia," 2010: 〈http:// www.psa.org.au / download / standards / competency-standards-complete.pdf $\rangle$, cited 30 June, 2014

4) Hart D., "Authentic Assessment: A Handbook for Educators," Dale Seymour Publications, Upper Saddle River, 1992.

5) Matsushita K., Kyoto University researches in higher education, 18, 75-114 (2012) .

6) Ministry of Education, Culture, Sports, Science and Technology, Central Council for Education, "Aratana mirai wo kizuku tameno daigaku kyouiku no sitsuteki tenkan ni mukete," 2012: 〈http://www.mext.go.jp/b_ menu / shingi / chukyo / chukyo0 / toushin / 1325047.htm $\rangle$, cited 30 July, 2014.

7) The Pharmaceutical Society of Japan, "Report on the 3rd advanced workshop for pharmaceutical teachers," 2014: 〈http:// www.pharm.or.jp/kyoiku/ $\rangle$, cited 30 July, 2014. 